\title{
Questionnaires can reflect the severity of electrophysiological findings In diabetic patients
}

\author{
Ozlem Ergin Beton $M D$, Hesna Bektas $M D$ \\ Department of Neurology, Ankara City Hospital, Ankara, Turkey
}

\begin{abstract}
Objective: The aim of this study was to determine whether a relationship exists between pain questionnaires, diabetic peripheral neuropathy, and the severity of electrophysiological findings. Methods: Patients with diabetes mellitus (DM) whose clinical signs and symptoms were found to be consistent with diabetic neuropathy were included in the present study in Ankara City Hospital Neurology Department between June 2020-January 2021. It was designed as a prospective cross-sectional study. Demographic characteristics, type and duration of DM, the onset of neuropathic complaints, systemic diseases, and DM treatments were noted. Blood tests were performed on all patients. Participants were administered the Douleur Neuropathique 4 Questions (DN4), Leeds Assessment of Neuropathic Symptoms and Signs (LANSS), and Numerical Rating Scale (NRS) questionnaires and an electrophysiological examination. Results: The study included 108 patients. A statistically significant correlation was found between the severity of electrophysiological findings and the age of patients, duration of diabetes, and treatment modality. Additionally, a statistically significant correlation was found between the severity of electrophysiological findings and blood urea nitrogen (BUN) levels and monocyte and platelet counts. According to the NRS, a significant relation was found between BUN values and the severity of pain experienced. The LANSS predicted the severity of electrophysiological findings at a significantly higher accuracy than other questionnaires.

Conclusion: Questionnaires can detect diabetic neuropathy, which is mostly asymptomatic, before the onset of DM complications. The LANSS questionnaire reflects the electrophysiological findings severity.
\end{abstract}

Keywords: Diabetes mellitus, electrophysiology, complications, questionnaires

\section{INTRODUCTION}

The most common chronic complication of type 1 and type 2 diabetes is diabetic peripheral neuropathy. ${ }^{1-2}$ Diabetic peripheral neuropathy (DPN) is a heterogeneous condition that has different clinical manifestations depending on the part of the nervous system involved. Even though severe neuropathic complaints occur in $10-20 \%$ of DPN patients ${ }^{3,4}$, it is known that up to $50 \%$ of patients are asymptomatic.

Neuropathic pain was defined as pain arising as a direct result of a lesion or disease influencing the somatosensorial system..$^{5-6}$ The most common type of neuropathic pain was reported to be painful DPN with a rate of 15.3-72.3/100.00 person-year. $^{7}$

For distal symmetrical polyneuropathy (DSPN), the most accurate diagnosis is made based upon clinical symptoms, findings, and electrodiagnostic examination. For a DSPN diagnosis, the electrodiagnostic examination is a standard, non-invasive, sensitive and widely used study. ${ }^{8}$

Besides, the development of questionnaires, which have been validated in various languages and can be readily conducted, has simplified diagnosis and management of this disease. The Douleur Neuropathique en 4 (DN4) and the Leeds Assessment of Neuropathic Symptoms and Signs (LANSS) questionnaires are commonly used all over the world. ${ }^{9}$ In distinguishing neuropathic pain from nociceptive pain, the sensitivity and specificity of the DN4 and LANSS were shown to be $80-83 \%$ and $80-90 \%$, respectively. ${ }^{10-12}$ In order to measure the severity of pain and monitor the response of patients to treatment, scales such as the numerical rating scale (NRS) are commonly used.

The present study aimed to determine whether there is a correlation between the results of pain questionnaires (DN4, LANSS, NRS) administered 
to diabetic patients who were considered to have DPN with neuropathic pain and the severity of electrophysiological findings in these patients. The study was also designed to determine which questionnaire reflected the severity of electrophysiological findings of length-dependent DPN more accurately.

\section{METHODS}

Patients between the ages of $18-70$ diagnosed with type 1 or type $2 \mathrm{DM}$ and referred by endocrinologists to the Neurology Department of Ankara City Hospital between June 2020-January 2021, who thought that their complaints are neuropathic, and whose clinical symptoms and signs were found to be consistent with DSPN were included in the present study. It was designed as a prospective cross-sectional study.

Demographic characteristics of patients, type and duration of DM; onset of neuropathic complaints, systemic diseases other than DM (hypertension, hyperlipidemia, coronary artery disease), DM treatments (diet, oral antidiabetic (OAD) insulin and OAD+insulin) were recorded. Blood investigation tests were examined for all patients.

Patients who were thought to be incapable of filling the questionnaires accurately due to illiteracy, mental retardation, and dementia, and those considered to have a more probable etiological factor for polyneuropathy (regular use of alcohol, history of cancer, thyroid pathology, history of chemotherapy, and history of GuillainBarre syndrome) were excluded from the study. In addition, patients over the age of 70 were not included in the study, as an age-associated nerve amplitude decrease may be observed in their sensory nerve amplitude.

All participants were administered DN4, LANSS, and NRS questionnaires by a single clinician (HB). Patients were divided into two groups according to DN4 and LANSS questionnaires, i.e., neuropathic pain and nociceptive pain (non-neuropathic pain). A LANSS score $\geq 12$ and a DN4 score $\geq 4$ were considered indicative of neuropathy. Subjective scores of pain by patients themselves were divided into five groups according to the NRS as follows: score 0 equals no pain, 1-3 equals mild pain, 4-6 equals moderate pain, 7-9 equals severe pain, and 10 is the worst pain that can be experienced.

Electrophysiological examination of all patients was performed by the same person $(O E B)$.
In the present study, the recommended standard electrophysiological examination for the distal symmetrical polyneuropathy diagnosis was used. ${ }^{8}$ Synergy On Nicolet ${ }^{\circledR}$ EDX was used for electrophysiological examination. In addition to the median, ulnar, sural, and superficial peroneal sensory nerve conductions, the median, ulnar, peroneal, and tibial motor nerve conductions were also measured. The skin temperature was maintained at about $32^{\circ} \mathrm{C}$. For interpretation of the results, standard values determined by our electrophysiology laboratory were used.

Patients were divided into four groups according to the results of the nerve conduction study (NCS), which was performed. The severity of electrophysiological findings was evaluated as follows: Normal: All nerve conduction studies in polyneuropathy protocol are normal; Mild: Only lower extremity sensory conduction is abnormal; Moderate: Abnormality of all sensory conduction. Severe: Abnormality of all sensory and motor nerve conductions.

\section{Statistical analysis}

Statistical analysis of the data was performed with the SPSS 20 (Statistical Package for Social Sciences) program. Descriptive statistics were expressed with mean \pm standard deviation, minimum and maximum value, frequency, and percentage. Fisher's Exact Test, Pearson ChiSquare, Kruskal-Wallis Test, and Mann-Whitney $\mathrm{U}$ test methods were used for analysis, and the method used was shown in Tables.

The local ethics committee approved the study protocol (Ankara City Hospital, E1-20-931).

\section{RESULTS}

One hundred and eight patients (58 male, 50 female) meeting inclusion criteria were included in the study. The values of the electrophysiological findings were divided into four groups (normal, mild, moderate, severe) in analysis. (Table 1)

There was a statistically significant correlation between the severity of electrophysiological findings in patients and age of patients, duration of diabetes, and treatment used for DM (Table 2). However, no correlation was found between severity of physiological findings and gender of the patients, type of diabetes, duration of neuropathic symptoms, and systemic diseases other than DM (hypertension, hyperlipidemia, coronary artery disease).

Of the 108 patients who received the DN4 questionnaire, 10 (9 male) scored below 4 . When 
Table 1: Electrophysiological values of patients divided in four groups (normal, mild, moderate, severe)

\begin{tabular}{lccccc}
\hline & $\begin{array}{c}\text { Normal } \\
(\mathbf{n = 2 9})\end{array}$ & $\begin{array}{c}\text { Mild } \\
(\mathbf{n = 3 4})\end{array}$ & $\begin{array}{c}\text { Moderate } \\
(\mathbf{n = 3 3})\end{array}$ & $\begin{array}{c}\text { Severe } \\
(\mathbf{n = 1 2})\end{array}$ & $\boldsymbol{P} *$ \\
\hline Median MNDL & $3.55+/-0.53$ & $3.99+/-0.90$ & $3.86+/-0.72$ & $5.65+/-2.17$ & $\mathbf{0 . 0 0 3}$ \\
Median CMAP & $10.61+/-3.32$ & $9.33+/-3.32$ & $7.38+/-3.03$ & $6.69+/-2.19$ & $<\mathbf{0 . 0 0 1}$ \\
Median MNCV & $56.18+/-4.59$ & $52.87+/-3.86$ & $50.52+/-4.09$ & $48.38+/-4.83$ & $<\mathbf{0 . 0 0 1}$ \\
Median sensory DL & $2.71+/-0.43$ & $2.85+/-1.01$ & $2.87+/-0.76$ & $3.32+/-1.35$ & $\mathbf{0 . 0 2 2}$ \\
Median SNAP & $13.91+/-5.76$ & $9.09+/-6.66$ & $7.60+/-5.08$ & $4.66+/-3.52$ & $<\mathbf{0 . 0 0 1}$ \\
Median SNCV & $50.50+/-8.52$ & $44.09+/-14.39$ & $42.93+/-10.93$ & $35.87+/-13.76$ & $<\mathbf{0 . 0 0 1}$ \\
Ulnar MNDL & $2.77+/-0.43$ & $3.28+/-3.44$ & $2.87+/-0.39$ & $3.47+/-0.59$ & $\mathbf{0 . 0 0 1}$ \\
Ulnar CMAP & $9.16+/-2.0$ & $9.33+/-2.33$ & $7.79+/-1.58$ & $4.03+/-0.88$ & $<\mathbf{0 . 0 0 1}$ \\
Ulnar MNCV & $56.19+/-5.70$ & $54.43+/-4.69$ & $53.60+/-4.32$ & $43.43+/-5.09$ & $<\mathbf{0 . 0 0 1}$ \\
Ulnar sensory DL & $1.97+/-0.31$ & $2.0+/-0.63$ & $2.20+/-0.34$ & $2.30+/-1.19$ & $\mathbf{0 . 0 0 3}$ \\
Ulnar SNAP & $11.08+/-3.74$ & $6.89+/-4.49$ & $5.98+/-3.25$ & $3.14+/-2.16$ & $<\mathbf{0 . 0 0 1}$ \\
Ulnar SNCV & $56.15+/-4.11$ & $49.27+/-14.09$ & $49.55+/-6.57$ & $35.35+/-17.41$ & $<\mathbf{0 . 0 0 1}$ \\
Tibial MNDL & $4.44+/-0.74$ & $4.72+/-0.92$ & $5.86+/-2.87$ & $4.27+/-2.66$ & $\mathbf{0 . 0 0 2}$ \\
Tibial CMAP & $8.33+/-2.62$ & $7.11+/-3.72$ & $3.31+/-2.46$ & $1.32+/-1.08$ & $<\mathbf{0 . 0 0 1}$ \\
Tibial MNCV & $44.90+/-4.09$ & $43.94+/-5.71$ & $37.47+/-8.59$ & $24.18+/-15.16$ & $<\mathbf{0 . 0 0 1}$ \\
Peroneal MNDL & $3.63+/-0.65$ & $4.07+/-0.75$ & $3.52+/-2.94$ & $1.89+/-2.83$ & 0.075 \\
Peroneal CMAP & $5.03+/-1.92$ & $3.95+/-1.94$ & $1.01+/-0.92$ & $0.41+/-0.69$ & $<\mathbf{0 . 0 0 1}$ \\
Peroneal MNCV & $49.98+/-7.59$ & $50.04+/-7.08$ & $25.85+/-19.04$ & $12.48+/-19.00$ & $<\mathbf{0 . 0 0 1}$ \\
Sural sensory DL & $2.74+/-0.42$ & $2.36+/-1.53$ & $2.04+/-1.74$ & $1.07+/-1.66$ & 0.127 \\
Sural SNAP & $14.44+/-3.92$ & $4.56+/-4.14$ & $3.19+/-3.23$ & $1.65+/-2.59$ & $<\mathbf{0 . 0 0 1}$ \\
Sural SNCV & $49.86+/-5.88$ & $32.53+/-19.58$ & $24.24+/-20.22$ & $14.07+/-21.28$ & $<\mathbf{0 . 0 0 1}$ \\
Sup. peroneal sensory DL & $2.69+/-0.37$ & $1.01+/-1.52$ & $1.0+/-1.68$ & $0.29+/-1.01$ & $<\mathbf{0 . 0 0 1}$ \\
Sup. peroneal SNAP & $10.31+/-5.10$ & $1.66+/-3.35$ & $0.99+/-1.75$ & $0.13+/-0.43$ & $<\mathbf{0 . 0 0 1}$ \\
Sup. peroneal SNCV & $49.24+/-5.50$ & $15.27+/-21.35$ & $9.39+/-15.81$ & $3.33+/-11.55$ & $<\mathbf{0 . 0 0 1}$ \\
\hline & & & & &
\end{tabular}

*Kruskal-Wallis test

(MNDL, motor nerve distal latency (ms); CMAP, compound muscle action potential $(\mu \mathrm{V})$; MNCV, motor nerve conduction velocity $(\mathrm{m} / \mathrm{s}) ;$ SNAP, sensory nerve action potential $(\mu \mathrm{V}) ; \mathrm{SNCV}$, sensory nerve conduction velocity. $(\mathrm{m} / \mathrm{s}))$ Significant values are highlighted in bold.

patients with a score below 4 (non-neuropathic group) were compared with those with a score of 4 or above (neuropathic group); it was established that in the former group, male patients and those who have no coronary disease obtained significantly lower scores on the DN4 ( $\mathrm{p}=0.015$ and $\mathrm{p}=0.032$, respectively).

Of the 108 patients who received the LANSS questionnaire, 51 (29 male; 22 female) obtained scores below 12. Patients with type 2 DM obtained significantly higher scores above 12 compared to type 1 DM groups. In type $2 \mathrm{DM}$, neuropathic pain was established to be significantly higher than that in type $1 \mathrm{DM}(\mathrm{p}=0.005)$. As in DN 4 questionnaire, the majority of patients with a score below 12 (non-neuropathic group), i.e., 82\%, had no coronary artery disease.

Subjective pain evaluation of patients was measured with NRS ( 0 no pain; 10 worst pain experienced). ${ }^{13}$ According to the NRS, the severity of pain increased significantly after the age of 51 $(p=0.042)$. In the present study, males accounted for the majority of patients with no pain or mild pain, while the effect of gender on pain decreased as the severity of pain increased, with no difference between genders in terms of most severe pain.

A statistically significant relation was found between the severity of electrophysiological findings and only three biochemical parameters (Table 3), namely, platelet, monocyte, and BUN 
Table 2: Characteristics of patients and the severity of electrophysiological findings

\begin{tabular}{|c|c|c|c|c|c|}
\hline & $\begin{array}{c}\text { Mild } \\
(n=34)\end{array}$ & $\begin{array}{c}\text { Normal } \\
(n=29)\end{array}$ & $\begin{array}{c}\text { Moderate } \\
(n=33)\end{array}$ & $\begin{array}{l}\text { Severe } \\
(n=12)\end{array}$ & $p$ \\
\hline Age & $55.76+/-10.30$ & $51.17+/-10.34$ & $60.64+/-8.71$ & $56.08+/-9.54$ & 0.003 \\
\hline Sex & & & & & $* *$ \\
\hline male & $16(47.1 \%)$ & $13(44.8 \%)$ & $19(57.6 \%)$ & $2(16.7 \%)$ & 0.017 \\
\hline female & $18(52.9 \%)$ & $16(55.2 \%)$ & $14(42.4 \%)$ & $10(83.3 \%)$ & \\
\hline DM Type & & & & & $*$ \\
\hline Type 1 & $4(11.8 \%)$ & $4(13.8 \%)$ & $1(3 \%)$ & $1(8.3 \%)$ & \\
\hline Type 2 & $30(88.2 \%)$ & $25(86.2 \%)$ & $32(97 \%)$ & $11(91.7 \%)$ & 0.418 \\
\hline $\begin{array}{l}\text { Duration of DM } \\
\text { (year) }\end{array}$ & $10.68+/-6.89$ & $8.45+/-6.45$ & $15.03+/-8.28$ & $17.25+/-6.89$ & $\begin{array}{c}* * * \\
0.001 \\
\end{array}$ \\
\hline $\begin{array}{l}\text { Duration of } \\
\text { neuropathic } \\
\text { symptoms (year) }\end{array}$ & $3.94+/-3.81$ & $3.34+/-2.77$ & $5.39+/-4.64$ & $4.25+/-3.52$ & 0.297 \\
\hline DM treatment & & & & & * \\
\hline Diet & $2(5.9 \%)$ & $2(6.9 \%)$ & $2(6.1 \%)$ & $0(0 \%)$ & \\
\hline OAD & $11(32.4 \%)$ & $17(58.6 \%)$ & $9(27.3 \%)$ & $0(0 \%)$ & 0.003 \\
\hline Insulin & $9(26.5 \%)$ & $6(20.7 \%)$ & $5(15.2 \%)$ & $6(50.0 \%)$ & \\
\hline OAD+Insulin & $12(35.3 \%)$ & $4(13.8 \%)$ & $17(51.5 \%)$ & $6(50.0 \%)$ & \\
\hline Hypertension & & & & & $* *$ \\
\hline No & $17(50.0 \%)$ & $16(55.2 \%)$ & $11(33.3 \%)$ & $6(50.0 \%)$ & \\
\hline Yes & $17(50.0 \%)$ & $13(44.8 \%)$ & $22(66.7 \%)$ & $6(50.0 \%)$ & 0.343 \\
\hline Hyperlipidemia & & & & & * \\
\hline No & $22(64.7 \%)$ & $21(72.4 \%)$ & $19(57.6 \%)$ & $6(50.0 \%)$ & \\
\hline Yes & $12(35.3 \%)$ & $8(27.6 \%)$ & $14(42.4 \%)$ & $6(50.0 \%)$ & 0.498 \\
\hline Coronary Artery & & & & & $*$ \\
\hline \multicolumn{6}{|l|}{ Disease } \\
\hline No & $27(79.4 \%)$ & $24(82.8 \%)$ & $21(63.6 \%)$ & $6(50.0 \%)$ & 0.092 \\
\hline Yes & $7(20.6 \%)$ & $5(17.2 \%)$ & $12(36.4 \%)$ & $6(50.0 \%)$ & \\
\hline
\end{tabular}

*Fisher exact test

**Pearson Chi-Square

***Kruskal-Wallis test

Significant values are highlighted in bold.

values $(\mathrm{p}$-values $=0.030,0.024$, and 0.023 , respectively).

In regard to biochemical parameters, no significant difference was found between patients with scores were below or above 4 on the DN4 and patients whose scores were below or above 12 on the LANSS. In terms of the NRS, a significant relation was found between BUN values and the severity of pain experienced. It was established that as BUN values increased, so did the severity of pain experienced by patients $(\mathrm{p}=0.023)$.

The relation between scores obtained in questionnaires and electrophysiological findings was shown in Tables 4 and 5. In patients obtaining a score of 4 or above on the DN4 questionnaire, the ulnar, tibial, and peroneal motor response amplitudes and sural sensory conduction velocity were found to be significantly lower than those of patients with a score below 4. In patients who obtained scores above 12 on the LANSS questionnaire, the median, ulnar, tibial, and peroneal motor response amplitudes (all motor nerve amplitudes evaluated) and peroneal motor conduction velocity were found to be significantly lower than other patients. However, no significant relation was found between DN4, NRS scores, and severity of electrophysiological findings ( $p$-value $=0.174$ and 0.207 , respectively). In the comparison of the aforementioned three questionnaires with each other, it was established that the LANSS survey predicted the severity of electrophysiological findings at a significantly higher rate than the others $(\mathrm{p}=0.041)$. 
Table 3: The relationship between biochemical results and the severity of electrophysiological findings

\begin{tabular}{|c|c|c|c|c|c|}
\hline & $\begin{array}{c}\text { Normal } \\
(n=29)\end{array}$ & $\begin{array}{c}\text { Mild } \\
(n=34)\end{array}$ & $\begin{array}{c}\text { Moderate } \\
(n=33)\end{array}$ & $\begin{array}{l}\text { Severe } \\
(n=12)\end{array}$ & $P *$ \\
\hline $\begin{array}{l}\text { Fasting blood } \\
\text { glucose }(\mathrm{mg} / \mathrm{dL})\end{array}$ & $156.10+/-63.80$ & $170.76+/-74.50$ & $158.06+/-59.58$ & $195.08+/-117.53$ & 0.812 \\
\hline $\begin{array}{l}\text { Postprandial } \\
\text { blood glucose } \\
(\mathrm{mg} / \mathrm{dL})\end{array}$ & $210.69+/-85.78$ & $232.56+/-102.25$ & $220.91+/-62.15$ & $262.00++/-130.44$ & 0.515 \\
\hline $\operatorname{HbA1C}(\%)$ & $8.01+/-1.56$ & $8.48+/-1.97$ & $8.49+/-1.70$ & $9.47+/-2.29$ & 0.279 \\
\hline $\begin{array}{l}\mathrm{HbA} 1 \mathrm{C}(\mathrm{mmol} / \\
\mathrm{mol})\end{array}$ & $64.24+/-16.62$ & $69.24+/-21.46$ & $69.34+/-18.51$ & $80.0+/-24.87$ & 0.314 \\
\hline $\begin{array}{l}\text { Mean glucose } \\
\text { measured by } \\
\text { mmol }(\mathrm{mg} / \mathrm{dL})\end{array}$ & $182.76+/-47.53$ & $196.61+/-59.29$ & $195.62+/-48.68$ & $232.50+/-66.42$ & 0.151 \\
\hline $\begin{array}{l}\text { Hemoglobin } \\
(\mathrm{g} / \mathrm{dL})\end{array}$ & $14.12+/-1.44$ & $13.97+/-1.78$ & $13.48+/-1.71$ & $14.08+/-1.68$ & 0.312 \\
\hline $\begin{array}{l}\text { Neutrophil count } \\
\left(\mathrm{x} 10^{\wedge} \mathrm{g} / \mathrm{L}\right)\end{array}$ & $4.54+/-1.41$ & $4.33+/-1.23$ & $5.18+/-1.95$ & $5.46+/-1.16$ & 0.074 \\
\hline $\begin{array}{l}\text { Lymphocyte } \\
\text { count }\left(x 10^{\wedge} 9 / \mathrm{L}\right)\end{array}$ & $2.24+/-0.61$ & $2.21+/-0.61$ & $2.19+/-0.73$ & $2.35+/-0.74$ & 0.935 \\
\hline $\begin{array}{l}\text { Platelet count } \\
\left(\mathrm{x} 10^{\wedge} 9 / \mathrm{L}\right)\end{array}$ & $281.79+/-57.74$ & $273.24+/-82.04$ & $256.39+/-85.89$ & $309.50+/-64.42$ & 0.030 \\
\hline $\begin{array}{l}\text { Monocyte count } \\
\left(\mathrm{x} 10^{\wedge} 9 / \mathrm{L}\right)\end{array}$ & $0.41+/-0.12$ & $0.42+/-0.16$ & $0.45+/-0.12$ & $0.52+/-0.12$ & 0.024 \\
\hline HDL (mg/dL) & $44.86+/-10.36$ & $44.38+/-11.09$ & $44.09+/-8.77$ & $42.25+/-9.26$ & 0.820 \\
\hline $\mathrm{LDL}(\mathrm{mg} / \mathrm{dL})$ & $112.34+/-34.25$ & $107.53+/-32.37$ & $106.97+/-35.29$ & $125.58+/-41.83$ & 0.543 \\
\hline $\begin{array}{l}\text { Triglyceride } \\
(\mathrm{mg} / \mathrm{dL})\end{array}$ & $191.38+/-70.30$ & $196.25+/-182.95$ & $183.27+/-79.56$ & $188.92+/-53.97$ & 0.311 \\
\hline BUN (mg/dL) & $28.10+/-8.17$ & $34.02+/-9.20$ & $36.76+/-15.86$ & $35.86+/-13.23$ & 0.023 \\
\hline $\begin{array}{l}\text { Serum creatinine } \\
\mathrm{mg} / \mathrm{dL}\end{array}$ & $0.79+/-0.17$ & $0.86+/-0.27$ & $0.87+/-0.33$ & $0.94+/-0.23$ & 0.259 \\
\hline $\begin{array}{l}\mathrm{eGFR}(\mathrm{ml} / \\
\left.\mathrm{m} / 1.73 \mathrm{~m}^{2}\right)\end{array}$ & $98.86+/-13.26$ & $92.03+/-24.41$ & $86.48+/-21.51$ & $85.08+/-16.10$ & 0.052 \\
\hline
\end{tabular}

HDL, High Density Lipoprotein; LDL, Low Density Lipoprotein; BUN, Blood Urea Nitrogen; eGFR, Estimated Glomerular Filtration Rate.

* Kruskal-Wallis test

Significant values are highlighted in bold.

\section{DISCUSSION}

The most typical and common diabetic polyneuropathy is symmetrical and lengthdependent, and legs are first involved. As the disease has an insidious course (i.e., slow-onset and progressive), the patient should be questioned about neuropathy to recognize the disease. ${ }^{14} \mathrm{All}$ types of peripheral neuropathy (PNP) that develop in diabetic patients may lead to foot ulcers, with peripheral neuropathy as the main cause of these ulcers. ${ }^{15,16}$ Delaying diagnosis increases the risk of foot ulcers, infection, gangrene, and, ultimately, amputation; hence, the mortality rate. ${ }^{17}$ In DM patients, the estimated life-long incidence of foot ulcers associated with undiagnosed peripheral neuropathy is around $15-25 \% .{ }^{18}$ Similarly, in the present study, although a widespread sensorimotor neuropathy was electrophysiologically detected in 12 out of 128 patients, none were previously diagnosed with PNP.

In the present study, the severity of electrophysiological findings was found to be significantly correlated with age and duration of 
Table 4: The relationship between scores obtained from DN4 questionnaires and electrophysiological parameters

\begin{tabular}{lccc}
\hline & $\begin{array}{c}\text { DN } \mathbf{4} \text { score } \\
\text { Under } \\
(\mathbf{n = 1 0})\end{array}$ & $\begin{array}{c}\text { DN 4 } \\
\mathbf{4} \text { and over } \\
\text { (n=98) }\end{array}$ & $\boldsymbol{P}^{*}$ \\
\hline Median MNDL & $3.91+/-0.85$ & $4.03+/-1.18$ & 0.996 \\
Median CMAP & $9.27+/-2.90$ & $8.74+/-3.47$ & 0.491 \\
Median MNCV & $53.34+/-5.03$ & $52.46+/-4.94$ & 0.945 \\
Median sensory DL & $2.75+/-0.56$ & $2.89+/-0.90$ & 0.294 \\
Median SNAP & $12.12+/-7.55$ & $9.17+/-6.20$ & 0.219 \\
Median SNCV & $50.94+/-11.85$ & $43.89+/-12.47$ & 0.058 \\
Ulnar MNDL & $2.84+/-0.50$ & $3.06+/-2.05$ & 0.962 \\
Ulnar CMAP & $9.69+/-2.32$ & $8.07+/-2.47$ & $\mathbf{0 . 0 4 8}$ \\
Ulnar MNCV & $54.64+/-3.52$ & $53.31+/-6.29$ & 0.332 \\
Ulnar sensory DL & $2.11+/-0.19$ & $2.08+/-0.61$ & 0.730 \\
Ulnar SNAP & $8.30+/-4.61$ & $7.22+/-4.46$ & 0.442 \\
Ulnar SNCV & $52.90+/-5.21$ & $49.33+/-12.46$ & 0.521 \\
Tibial MNDL & $4.90+/-0.58$ & $4.95+/-2.09$ & 0.932 \\
Tibial CMAP & $7.88+/-3.68$ & $5.40+/-3.75$ & $\mathbf{0 . 0 3 7}$ \\
Tibial MNCV & $42.69+/-2.63$ & $39.75+/-10.52$ & 0.532 \\
Peroneal MNDL & $4.14+/-1.51$ & $3.48+/-2.07$ & 0.836 \\
Peroneal CMAP & $4.11+/-1.98$ & $2.83+/-2.42$ & $\mathbf{0 . 0 4 8}$ \\
Peroneal MNCV & $48.85+/-7.33$ & $37.40+/-20.03$ & 0.087 \\
Sural sensory DL & $3.00+/-0.79$ & $2.14+/-1.52$ & 0.186 \\
Sural SNAP & $9.57+/-6.87$ & $6.18+/-6.00$ & 0.089 \\
Sural SNCV & $46.43+/-8.03$ & $31.19+/-21.31$ & $\mathbf{0 . 0 1 5}$ \\
Sup. peroneal sensory DL & $2.09+/-1.52$ & $1.30+/-1.54$ & 0.088 \\
Sup. peroneal SNAP & $4.87+/-5.03$ & $3.48+/-5.33$ & 0.174 \\
Sup. peroneal SNCV & $30.88+/-21.90$ & $20.29+/-23.25$ & 0.185 \\
\hline
\end{tabular}

*Mann-Whitney U Test

Significant values are highlighted in bold.

diabetes, the use of insulin or combined insulin plus OAD treatments, a LANSS questionnaire score above 12 , and increased BUN, platelet, and monocyte levels.

Typical chronic symmetrical (lengthdependent) diabetic peripheral neuropathy is one of the most common complications of diabetes. ${ }^{19}$ It is known that DSPN occurs in at least $50 \%$ of cases, especially patients with diabetes over 25 years of age. Accordingly, age, duration of DM, and $\mathrm{HbA} 1 \mathrm{c}$ levels are the most important risk factors for the development of DSPN ${ }^{20}$ Similar to previous studies ${ }^{21,22}$, in the present study, it was observed that the duration of diabetes is the main factor determining peripheral nerve function.

In the present study, it was determined that in patients with a DN4 score below 4 and a LANSS score below 12, coronary artery disease occurred at a significantly higher rate $(\mathrm{p}=0.032$ and $\mathrm{p}=0.022)$. Nevertheless, no statistically significant correlation was found between the electrophysiological severity of neuropathy and cardiovascular disease. This may be due to the relatively lower number of patients with severe neuropathy compared to other groups. The fact that hypertension and hyperlipidemia were not found to be correlated with the severity of electrophysiological findings may be attributed to the frequent coexistence of these diseases with DM independent of neuropathy. There were few patients with severe neuropathy in the present study, which may be due to the inclusion of patients who had not previously undergone any electrophysiological examination and the higher likelihood of patients who had already been diagnosed with severe neuropathy.

Various questionnaires, such as LANSS and DN4, are based on a bedside examination of clinical dysfunction. These questionnaires are simple tools that can be easily used by physicians 
Table 5: The relationship between scores obtained in LANSS questionnaires and electrophysiological findings

\begin{tabular}{lccc}
\hline & $\begin{array}{c}\text { LANSS score } \\
\text { Under 12 } \\
(\mathbf{n = 5 1})\end{array}$ & $\begin{array}{c}\text { LANSS score } \\
\mathbf{1 2} \text { and over } \mathbf{1 2} \\
(\mathbf{n = 5 7 )}\end{array}$ & $\boldsymbol{P} *$ \\
\hline Median MNDL & $3.85+/-0.84$ & $4.16+/-1.36$ & 0.231 \\
Median CMAP & $9.69+/-3.29$ & $7.98+/-3.34$ & $\mathbf{0 . 0 0 9}$ \\
Median MNCV & $52.89+/-4.44$ & $52.23+/-5.35$ & 0.707 \\
Median sensory DL & $2.81+/-0.79$ & $2.93+/-0.94$ & 0.575 \\
Median SNAP & $9.85+/-6.47$ & $9.07+/-6.29$ & 0.473 \\
Median SNCV & $45.66+/-13.27$ & $43.54+/-11.86$ & 0.197 \\
Ulnar MNDL & $3.26+/-2.81$ & $2.84+/-0.49$ & 0.413 \\
Ulnar CMAP & $8.74+/-2.38$ & $7.76+/-2.52$ & $\mathbf{0 . 0 5 0}$ \\
Ulnar MNCV & $54.24+/-6.01$ & $52.71+/-6.13$ & 0.122 \\
Ulnar sensory DL & $1.97+/-0.52$ & $2.19+/-0.62$ & $\mathbf{0 . 0 0 8}$ \\
Ulnar SNAP & $8.02+/-4.76$ & $6.70+/-4.12$ & 0.165 \\
Ulnar SNCV & $50.89+/-11.93$ & $48.55+/-12.07$ & 0.088 \\
Tibial MNDL & $4.89+/-1.20$ & $4.99+/-2.52$ & 0.829 \\
Tibial CMAP & $6.58+/-3.95$ & $4.78+/-3.47$ & $\mathbf{0 . 0 1 3}$ \\
Tibial MNCV & $42.11+/-8.98$ & $38.16+/-10.71$ & 0.059 \\
Peroneal MNDL & $3.96+/-1.89$ & $3.17+/-2.08$ & 0.453 \\
Peroneal CMAP & $3.50+/-2.46$ & $2.45+/-2.27$ & $\mathbf{0 . 0 1 7}$ \\
Peroneal MNCV & $43.93+/-15.31$ & $33.57+/-21.54$ & $\mathbf{0 . 0 1 8}$ \\
Sural sensory DL & $2.42+/-1.37$ & $2.04+/-1.57$ & 0.393 \\
Sural SNAP & $7.41+/-6.32$ & $5.68+/-5.89$ & 0.128 \\
Sural SNCV & $36.28+/-19.58$ & $29.30+/-21.66$ & 0.083 \\
Sup. peroneal sensory DL & $1.60+/-1.60$ & $1.17+/-1.47$ & 0.175 \\
Sup. peroneal SNAP & $4.36+/-5.34$ & $2.93+/-5.21$ & 0.063 \\
Sup. peroneal SNCV & $24.94+/-23.68$ & $17.99+/-22.53$ & 0.110 \\
\hline
\end{tabular}

*Mann-Whitney U Test

Significant values are highlighted in bold.

not directly involved with pain issues and can rapidly yield information in clinical settings..$^{11,10}$ In regard to NRS, it is a scoring system utilized in many clinical studies and established to be highly efficient at determining subjective pain and response to treatment. ${ }^{13-16}$ In terms of the questionnaire results: a DN4 score below 4 (compared to scores above 4) displayed a significant decrease in ulnar, tibial, and peroneal motor response amplitudes and sural sensory response conduction velocity; a LANSS score above 12 (compared to scores below 12) showed a significant decrease in all motor response amplitudes (median, ulnar, tibial, and peroneal). The NRS, which is a method for evaluating subjective pain, was not successful in predicting the severity of electrophysiological findings. In the present study, a significant correlation was found between the LANSS questionnaire developed by Bennett, aiming to demonstrate that pain develops predominantly via a neuropathic mechanism, and electrophysiologically-detected axonal loss. ${ }^{10}$ In a study by Spallone et al. ${ }^{23}$, electrophysiological findings were compared between 3 groups of diabetic patients (i.e., painful sensorimotor neuropathy, sensorimotor polyneuropathy, and a group without sensorimotor neuropathy). It was found that there was a statistically significant difference between the painful sensory polyneuropathy group and the group without diabetic sensory polyneuropathy in regard to lower extremity nerve conductions, which was most marked in the sural nerve conduction velocity. In the same study, a significant relation was found between DN4 scores and all neurological and electrophysiological measurements. ${ }^{23}$ To our knowledge, there is no previous study investigating the relation between 
LANSS scores and nerve conduction velocities.

The evaluation of the relationship between laboratory data and electrophysiological findings established that there was a positive correlation between BUN and thrombocytes and monocytes counts and the severity of electrophysiological findings. The relation between thrombocytes and the development and progression of microvascular complications of diabetes is known. ${ }^{24}$ In a previous study investigating the relationship between glycemic control and thrombocyte activity in type $2 \mathrm{DM}$ patients, a significant correlation was found between poor glycemic control and mean platelet volume (MPV). However, no similar relationship was found with the thrombocyte count. ${ }^{25}$ It was also observed that an increase in thrombocyte: lymphocyte ratio increased the risk of diabetic foot and foot ulcers. ${ }^{26}$ In another study investigating the relation between hematological parameters and the severity of electrophysiological findings, similar to the present study, a significant negative correlation was found between the posterior tibial nerve's compound muscle action potential (CMAP) amplitudes and the number of monocytes. ${ }^{27}$ We presumed that this was associated with pro-inflammatory substances such as protease and cytokines, released from monocytes and macrophages derived from monocytes in diabetic patients, which lead to oxidative stress and, hence, the degradation of myelin and impairment of nerve regeneration. ${ }^{28}$

In the present study, BUN values were found to correlate with the severity of electrophysiological findings. Comparably, in another study, it was reported that BUN and thrombocyte values increased 1-year mortality risks of lower extremity amputations associated with peripheral artery disease or diabetes. ${ }^{29}$

Consistent with the present study, in a study by Raputova et al..$^{30}$, the pain-severity classification displayed a significantly higher number of men in the group with no/mild pain. In contrast, the male : female ratio was equal in the moderate/severe pain group. Inconsistent with the present study, which established that after the age of 51, pain severity significantly increased, their study found no relationship between age and severity of pain. In addition, in their study, the severity of pain was found to correlate with eGFR and serum creatinine levels, whereas in the present study, a significant correlation was found between BUN values and severity of pain $(\mathrm{p}=0.023)$. No significant correlation was found between the biochemical parameters and pain character (neuropathic vs. nociceptive). There were no differences in any of the evaluated nerve conduction study (NCS) parameters between pain subgroups.$^{30}$

One of the main limitations of the present study was that using the routine electrophysiological investigation we carried out, only the large fiber functions could be evaluated. Intradermal nerve fiber density measurement with skin biopsy is considered the gold standard in diagnosis but was not carried out in our study, as it is invasive; as such, pure small fiber neuropathy could not be detected..$^{31}$ Therefore, in our study, pure small fiber neuropathy (SFN) cases whose main characteristics were pain ${ }^{32}$, which is known to lead to length-dependent pattern neuropathic pain and frequently missed, could not be diagnosed. As the group of 33 patients (which include patients without large nerve fiber involvement and with normal electrophysiological findings) may include pure SFN patients, significant correlations may not have been found between pain severity and severity of electrophysiological findings. In this respect, further and larger studies are required to determine the factors that influence the pain severity in neuropathic pain. Moreover, they should also evaluate factors such as BMI, any history of peripheral artery disease, mood, quality of life, and sleep disorders.

In conclusion, according to the results of the present study, neuropathic pain questionnaires, which have been recommended for screening so far and can be administered in a short time, should be used more commonly. It is evident that, as the duration of diabetes is prolonged, peripheral neuropathy complications develop. Evaluations of diabetic patients at certain intervals using, at least, these questionnaires will reduce disability and mortality before the development of foot ulcers, gangrene, and amputation. In the present study, it was established that the formulation of sentences from the LANSS questions was more comprehensible to patients. The resultant scores were associated with the degree of electrophysiologically-detected nerve injury, particularly axonal loss. As the perception of pain is variable, it was believed that the pain scores entered by patients themselves are quite subjective and do not reflect the electrophysiological findings of length-dependent diabetic peripheral neuropathy. Further clinical studies confirming our results and investigating the correlation between neuropathic pain scales and electrophysiological findings are required.

\section{REFERENCES}

1. International Diabetes Federation. IDF Diabetes Atlas. 6th ed. Brussels: International Diabetes Federation; 2013. http://www.idf.org/diabetesatlas. Accessed 
May 16, 2014.

2. Sasaki H, Kawamura N, Dyck PJ, Dyck PJB, Kihara M, Low PA. Spectrum of diabetic neuropathies. Diabetol Int 2020;11(2):87-96.

3. Argoff CE, Cole BE, Fishbain DA, Irving GA. Diabetic peripheral neuropathic pain: clinical and quality of-life issues. Mayo Clin Proc 2006;81(4 Suppl):S3-11.

4. Iqbal Z, Azmi S, Yadav R, et al. Diabetic peripheral neuropathy: epidemiology, diagnosis, and pharmacotherapy. Clin Ther 2018;40(6):828-49.

5. Merskey H, Bogduk N. Classification of chronic pain. Seattle: IASP Press; 1994.

6. Treede RD, Jensen TS, Campbell JN, et al. Neuropathic pain: redefinition and a grading system for clinical and research purposes. Neurology 2008;70(18):1630-5

7. van Hecke O, Austin SK, Khan RA, Smith BH, Torrance N. Neuropathic pain in the general population: a systematic review of epidemiological studies. Pain 2014;155(4):654-62.

8. England JD, Gronseth GS, Franklin G, et al. Distal symmetric polyneuropathy: a definition for clinical research: report of the American Academy of Neurology, the American Association of Electrodiagnostic Medicine, and the American Academy of Physical Medicine and Rehabilitation. Neurology 2005;64(2):199-207.

9. Attal N, Bouhassira D, Baron R. Diagnosis and assessment of neuropathic pain through questionnaires. Lancet Neurol 2018;17:456-66.

10. Bennett M. The LANSS Pain Scale: the Leeds assessment of neuropathic symptoms and signs. Pain 2001;92:147-57.

11. Unal-Cevik I, Sarioglu-Ay S, Evcik D. A comparison of the DN4 and LANSS questionnaires in the assesment of neuropathic pain: validity and reliability of the Turkish version of DN4. J Pain 2010;11(11):1129-35.

12. Yucel A, Senocak M, Orhan EK, Cimen A, Ertas M. Results of the Leeds assessment of neuropathic symptoms and signs pain scale in Turkey: a validation study. J Pain 2004; 5(8):427-32.

13. Farrar JT, Young JP Jr, LaMoreaux L, Werth JL, Poole RM. Clinical importance of changes in chronic pain intensity measured on an 11-point numerical rating scale. Pain 2001;94:149-58.

14. Selvarajah D, Kar D, Khunti K, et al. Diabetic peripheral neuropathy: advances in diagnosis and strategies for screening end early intervention. Lancet Diabetes Endocrinol 2019;7(12):938-48.

15. Monteiro-Soares M, Boyko EJ, Ribeiro J, Ribeiro I, Dinis-Ribeiro M. Predictive factors for diabetic foot ulceration: a systematic review. Diabetes Metab Res Rev 2012;28:574-600

16. Bus SA, van Deursen RW, Armstrong DG, Lewis JE, Caravaggi CF, Cavanagh PR. Footwear and offloading interventions to prevent and heal foot ulcers and reduce plantar pressure in patients with diabetes: a systematic review. Diabetes Metab Res Rev 2016;32(Suppl 1):99-118.

17. Pop-Busui R, Boulton AJM, Feldman EL, et al. Diabetic neuropathy: a position statement by the American Diabetes Association. Diabetes Care 2017;40:136-54.
18. Singh N, Armstrong DG, Lipsky BA. Preventing foot ulcers in patients with diabetes. JAMA 2005;293:21728.

19. Abraham A, Breiner A, Barnett C, et al. Uric acid levels correlate with the severity of diabetic sensorimotor polyneuropathy. J Neurol Sci 2017;379:94-8.

20. Tesfaye S, Boulton AM, Dyck PJ, et al. Diabetic neuropathies: update on definitions, diagnostic criteria, estimation of severity and treatments. Diabetes Care 2010;33(10):2285-93

21. Valensi P, Giroux C, Seeboth-Ghalayini B, Attali, JR. Diabetic peripheral neuropathy: effects of age, duration of diabetes, glycemic control, and vascular factors. J Diabetes Complications 1997;11(1):27-34.

22. Tesfaye S, Chaturvedi N, Eaton SEM, et al. Vascular risk factors and diabetic neuropathy. $N$ Engl J Med 2005;352(4):341-50

23. Spallone V, Morganti R, Amato CD, Greco1 C, Cacciotti L, Marfia GA. Validation of DN4 as a screening tool for neuropathic pain in painful diabetic polyneuropathy. Diabet Med 2011;29:578-85.

24. Cho NH, Becker DJ, Ellis D, Kuller LH, Drash AL, Orchard TJ. Spontaneous whole blood platelet aggregation, hematological variables and complications in insulin-dependent diabetes mellitus: the Pittsburgh Epidemiology of Diabetes Complications Study. J Diabetes Complications. 1992;6(1):12-8

25. Demirtunc R, Duman D, Basar M, Bilgi M, Teomete $\mathrm{M}$, Garip T. The relationship between glycemic control and platelet activity in type 2 diabetes mellitus. J Diabetes Complications 2009;23(2):89-94.

26. Mineoka Y, Ishii M, Hashimoto Y, Yamashita A, Nakamura N, Fukui M. Platelet to lymphocyte ratio correlates with diabetic foot risk and foot ulcer in patients with type 2 diabetes. Endocr $J$ 2019;66(10):905-13.

27. Vural G, Gümüşyayla Ş. Monocyte-to-high density lipoprotein ratio is associated with a decreased compound muscle action potential amplitude in patients with diabetic axonal polyneuropathy. Medicine (Baltimore) 2018; 97(42):e12857.

28. Alvarado-Vazquez PA, Grosick RL, MorachoVilrriales C, Ward E, Threatt T, Romero-Sandoval EA. Cytokine production capabilities of human primary monocyte-derived macrophages from patients with diabetes mellitus type 2 with and without diabetic peripheral neuropathy. J Pain Res 2019;12 69-81.

29. Norvell DC, Thompson ML, Boyko EJ, et al.Mortality prediction following non-traumatic amputation of the lower extremity. Br J Surg 2019;106(7):879-88.

30. Raputova J, Srotova I, Vlckova E, et al. Sensory phenotype and risk factors for painful diabetic neuropathy: a cross-sectional observational study. Pain 2017;158:2340-53.

31. Terkelsen AJ, Karlsson P, Lauria G, Freeman R, Finnerup NB, Jensen TS. The diagnostic challenge of small fibre neuropathy; clinical presentations, evaluations and causes. Lancet Neurol 2017;16:93444.

32. Brouwer BA, Kuijk SMJ, Bouwhuis A, et al. The pain dynamics of small fiber neuropathy. J Pain 2019;20(6):655-63. 